\title{
The Counterion Effect on the Steric Course of the Cationic Polymerization of Isobutyl Vinyl Ether*
}

\author{
Toyoki Kunitake, Kunihide Takarabe, and Shun-ichi Tsugawa \\ Department of Organic Synthesis, Faculty of Engineering, \\ Kyushu University, Fukuoka 812, Japan.
}

(Received January 19, 1976)

\begin{abstract}
The cationic polymerization of isobutyl vinyl ether was conducted with a variety of triphenylmethyl salts as initiators, and the steric structure of the polymer was determined from the methylene dyad peaks in the ${ }^{13} \mathrm{C}-\mathrm{NMR}$ spectra. The fraction of the isotactic dyad increased with the increase in the counteranion size from $\mathrm{BF}_{4}-$ to $\mathrm{ClO}_{4}^{-}$to $\mathrm{BCl}_{4}^{--}$, and then decreased: a trend similar to that observed for $\alpha$-methylstyrene. The correlation seems to be more complex for larger counteranions, and a periodical influence was clearly noticed. These results were explained by considering the tightness of the propagating ion-pair. Pentacoordinate counteranions showed peculiar influences in that the polymer structure was influenced by the counteranion concentration. The molecular weight distribution was unimodal, suggesting that a single propagating species is present.

KEY WORDS Cationic Polymerization / Isobutyl Vinyl Ether / Steric Course / Counteranion /
\end{abstract}

The present paper is concerned with the use of various triphenylmethyl salts in the cationic polymerization of isobutyl vinyl ether, for the purpose of establishing the effect of counteranions on the steric course of cationic propagation.

Some years ago, we carried out cationic polymerization of isobutyl vinyl ether $(\mathbf{I})^{1}$ and $\alpha$ methylstyrene $(\mathbf{I I})^{2}$ with five kinds of triphenylmethyl salts. These results suggested that the size and shape of the counteranions were important factors in controlling the steric course of propagation. However, a systematic variation of the counteranion was desirable in order to establish the correlation between the steric course and the counteranion structure. Recent studies on the cationic polymerization of $\alpha$-methylstyrene $^{3}$ and spiro[2,4]hepta-4,6-diene (III) ${ }^{4}$ by using a larger number of triphenylmethyl salts showed that the polymer structures were correlated with the nature of the counteranion in fairly simple ways. Therefore, we undertook a similar study with isobutyl vinyl ether. A preliminary report of this study was given elsewhere. ${ }^{5}$

\footnotetext{
* Contribution No. 390 from this department.
}

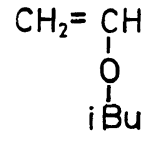

I<smiles>C=C(C)c1ccccc1</smiles>

II

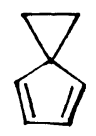

III

\section{EXPERIMENTAL}

\section{Materials}

Commercial isobutyl vinyl ether was washed with aqueous alkali, dried over potassium hydroxide pellets, refluxed over sodium metal, and distilled. It was redistilled from sodium metal just before use: bp $82.7-83.0^{\circ} \mathrm{C}$. Polymerization solvents were purified according to the usual methods and stored over molecular sieves. The preparation of all the triphenylmethyl salts employed was described elsewhere. ${ }^{3}$

Tetrabutylammonium pentachlorostanate $\left(\mathrm{Bu}_{4^{-}}\right.$ $\left.\mathrm{N}^{+} \mathrm{SnCl}_{5}^{-}\right)$was obtained as follows: $0.9 \mathrm{~g}(0.0035$ $\mathrm{mol}$ ) of freshly distilled tin tetrachloride was slowly added under nitrogen with vigorous stirring to $1 \mathrm{~g}(0.0036 \mathrm{~mol})$ of commercial tetrabutylammonium chloride in $15 \mathrm{~m} l$ of $\mathrm{CCl}_{4}$ cooled in an ice bath. White powdery precipitates were filtered and washed with $\mathrm{CCl}_{4}$ under dry 
nitrogen, and recrystallized from $\mathrm{CH}_{2} \mathrm{Cl}_{2}$ and $\mathrm{CCl}_{4}, \mathrm{mp} 125^{\circ} \mathrm{C}$, yield $1.47 \mathrm{~g}(79 \%)$.

Anal. Calcd for $\mathrm{C}_{16} \mathrm{H}_{36} \mathrm{NSnCl}_{5}$ : C, 35.68; $\mathrm{H}$, $6.74 ; \mathrm{N}, 2.60 \%$. Found: C, 35.54; H, 6.94; $\mathrm{N}, 2.40 \%$.

\section{Polymerization}

Polymerization was carried out in a $100-\mathrm{m} l$ flask which had been flamed thoroughly under dry nitrogen. Catalyst solutions were prepared in a steel dry box under nitrogen. Solvent and catalyst solutions were introduced into the flask sealed with a rubber cap using the three-needle technique. ${ }^{6}$ In some cases Schlenk-type ampoules were used and solutions were pipetted in under nitrogen stream. Cold monomer was then added to the reaction mixture with magnetic stirring at $-76^{\circ} \mathrm{C}$. The polymerization was terminated with a small amount of a pyridinemethanol mixture and the solution was poured into excess methanol. When a large amount of $n$-hexane was used, the solvent was evaporated after termination, and the residue was dissolved in $\mathrm{CH}_{2} \mathrm{Cl}_{2}$ and poured into excess methanol. The polymer was separated by decantation, washed well with methanol, and dried in vacuo. Purifications were carried out by reprecipitation (usually 1 or 2 times) from $\mathrm{CH}_{2} \mathrm{Cl}_{2}$ and methanol, and freeze-drying of benzene solutions.

\section{Measurements}

The precipitation temperature of the polymer, $T_{\mathrm{p}}$, was measured in methyl ethyl ketone $(0.5$ $\mathrm{w} / \mathrm{v} \%$ solution) according to the published procedure. ${ }^{1,7}{ }^{13} \mathrm{C}$-NMR spectra were obtained with complete proton decoupling at $22.6 \mathrm{MHz}$ by using a BRUKER WH-90 FT spectrometer. Usually 5000 scans were accumulated. Gel permeation chromatograms were obtained with a Toyo Soda HLC-801A instrument fitted with two columns of cross-linked polystyrene gel having pore sizes of $2.5 \times 10^{2}$ and $10^{4} \AA$. Samples were subjected to analysis as $0.5-\%$ solution in tetrahydrofuran.

\section{RESULTS AND DISCUSSION}

\section{Polymerization}

The general trend of the cationic polymerization of isobutyl vinyl ether by triphenylmethyl initiators has been given. ${ }^{1}$ The polymerization was generally fast and high conversions $(>70 \%)$ were attained in $10-20 \mathrm{~min}$ with most initiators, except for the $80: 20(\mathrm{v} / \mathrm{v})$ hexane- $-\mathrm{CH}_{2} \mathrm{Cl}_{2}$ medium.

\section{Polymer Structure}

The steric structure of poly(isobutyl vinyl ether) can be qualitatively determined by the precipitation temperature, $T_{\mathrm{p}}$, of the polymer in methyl ethyl ketone. Recently, however, Matsuzaki, et al. ${ }^{8}$ showed that the racemic and meso $\mathrm{CH}_{2}$ peaks appeared in the ${ }^{13} \mathrm{C}-\mathrm{NMR}$ spectrum. Figure 1 gives typical ${ }^{13} \mathrm{C}-\mathrm{NMR}$ spectra of the polymer. The amount of the isotatic dyad $P_{\mathrm{m}}$ was calculated from the relative peak area of the two $\mathrm{CH}_{2}$ peaks. The variation of $\boldsymbol{P}_{\mathrm{m}}$ for different polymer samples obtained under identical conditions was estimated to be at most \pm 0.02 . Figure 2 gives the plot of $P_{\mathrm{m}}$ and $T_{\mathrm{p}}$. The reproducibility of $T_{\mathrm{p}}$ was previously shown to be better than $\pm 0.5^{\circ} \mathrm{C}$ for a given sample. ${ }^{1}$ The linearity of the relation is fairly satisfactory for those plots of $T_{\mathrm{p}}$ above $-50^{\circ} \mathrm{C}$. Therefore, $P_{\mathrm{m}}$ for other polymers was estimated from $T_{\mathrm{p}}$ using this relation; the values

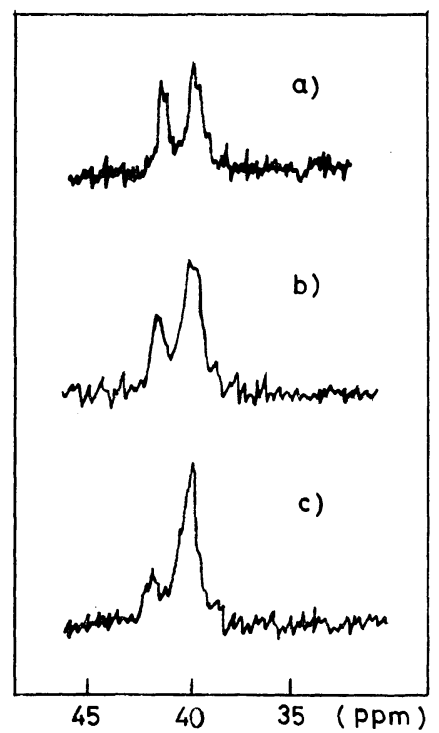

Figure 1. The methylene dyad in the ${ }^{13} \mathrm{C}-\mathrm{NMR}$ spectrum of poly(isobutyl vinyl ether): solvent, $\mathrm{CDCl}_{3}$; internal reference, TMS; polymerization condition, (a) $\mathrm{Ph}_{3} \mathrm{C}^{+} \mathrm{BF}_{4}^{-}, \mathrm{CH}_{2} \mathrm{Cl}_{2}$, (b) $\mathrm{Ph}_{3} \mathrm{C}^{+} \mathrm{InCl}_{4}{ }^{-}$, $5: 5(\mathrm{v} / \mathrm{v}) \mathrm{CH}_{2} \mathrm{Cl}_{2}$-hexane, (c) $\mathrm{Ph}_{3} \mathrm{C}^{+} \mathrm{TaCl}_{6}{ }^{-}, 2: 8$ (v/v) $\mathrm{CH}_{2} \mathrm{Cl}_{2}$-hexane. 


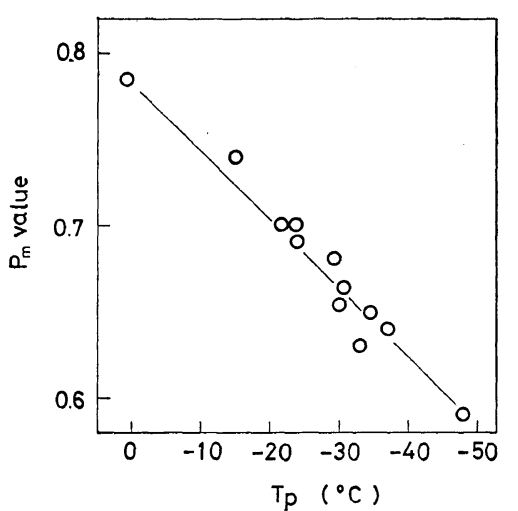

Figure 2. Relation between $P_{\mathrm{m}}$ and $T_{\mathrm{p}}$.

Table I. $P_{\mathrm{m}}$ values of poly(isobutyl vinyl ether)a

\begin{tabular}{lcccc}
\hline & \multicolumn{4}{c}{ Solvent } \\
\cline { 2 - 5 } Counterion & \multicolumn{3}{c}{$\mathrm{CH}_{2} \mathrm{Cl}_{2}-n$-hexane (vol ratio) } \\
\cline { 2 - 5 } & $10: 0$ & $5: 5$ & $3: 7$ & $2: 8$ \\
\hline $\mathrm{BF}_{4}^{-}$ & 0.57 & 0.62 & & 0.68 \\
$\mathrm{BCl}_{4}^{-}$ & 0.67 & 0.76 & 0.78 & 0.79 \\
$\mathrm{ClO}_{4}^{-}$ & & 0.66 & & \\
$\mathrm{AlCl}_{4}^{-}$ & 0.57 & 0.64 & 0.66 & 0.70 \\
$\mathrm{AlBr}_{4}^{-}$ & & 0.67 & & 0.73 \\
$\mathrm{GaCl}_{4}^{-}$ & 0.57 & 0.66 & 0.67 & 0.71 \\
$\mathrm{InCl}_{4}^{-}$ & 0.56 & 0.65 & 0.68 & 0.69 \\
$\mathrm{InBr}_{4}^{-}$ & 0.57 & 0.64 & 0.66 & 0.68 \\
$\mathrm{TlCl}_{4}^{-}$ & 0.56 & 0.71 & 0.74 & 0.77 \\
$\mathrm{SbCl}_{6}^{-}$ & 0.56 & 0.69 & 0.68 & $0.71-0.72$ \\
$\mathrm{TaCl}_{6}^{-}$ & 0.63 & 0.71 & & 0.79 \\
$\mathrm{SnCl}_{5}^{-}$ & 0.65 & $0.71-0.79^{\mathrm{b}}$ & 0.77 & 0.77 \\
$\mathrm{SnBrCl}_{4}^{-}$ & 0.63 & 0.72 & 0.78 & 0.80 \\
$\mathrm{SnClBr}_{4}^{-}$ & & 0.77 & 0.79 & 0.81 \\
$\mathrm{SnBr}_{5}^{-}$ & 0.61 & 0.79 & 0.80 & $0.83-0.86^{\mathrm{b}}$ \\
$\mathrm{ZrCl}_{5}^{-}$ & 0.61 & $0.68-0.72^{\mathrm{b}}$ & 0.74 & 0.76 \\
\hline${ }^{-}$ & & &
\end{tabular}

a $-76^{\circ} \mathrm{C}$; monomer, $0.71 \mathrm{M}$; initiator, 2-12 $\mathrm{mM}$.

b The polymer structure depends on the initiator concentration.

are summarized in Table $\mathrm{I}$. The $P_{\mathrm{m}}$ value decreased with increasing polarity of the medium, as already shown by the $T_{\mathrm{p}}$ variation. In $\mathrm{CH}_{2} \mathrm{Cl}_{2}, P_{\mathrm{m}}$ values are about 0.6 , indicating the prevailing atactic propagation. The fraction of the isotactic dyad increased to $0.7-0.8$ in the least polar medium $\left(80: 20(\mathrm{v} / \mathrm{v})\right.$ hexane $\left.-\mathrm{CH}_{2} \mathrm{Cl}_{2}\right)$. The $P_{\mathrm{m}}$ value with the pentacoordinate anion was affected by the initiator concentration in a

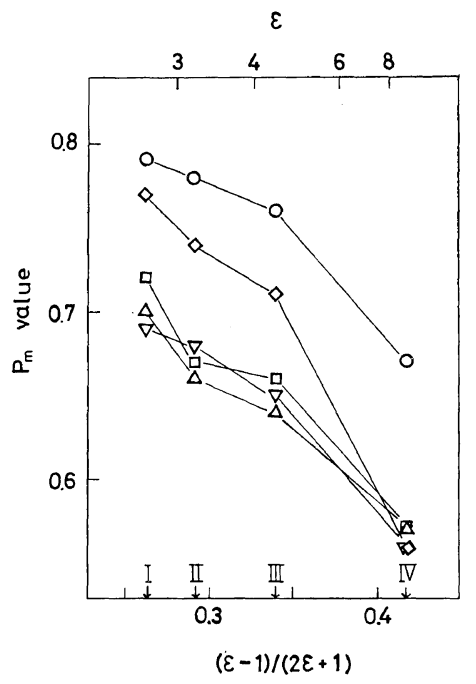

Figure 3. Influence of the solvent polarity on the polymer structure: counteranion, ( $\bigcirc) \mathrm{BCl}_{4}^{-},(\triangle)$ $\mathrm{AlCl}_{4}^{-},(\square) \mathrm{GaCl}_{4}^{-},(\nabla) \mathrm{InCl}_{4}^{-},(\diamond) \mathrm{TlCl}_{4}^{-}$; polymerization solvent, (I) $8: 2(\mathrm{v} / \mathrm{v}) n$-hexane- $\mathrm{CH}_{2} \mathrm{Cl}_{2}$, (II), $7: 3(\mathrm{v} / \mathrm{v}) \quad n$-hexane- $\mathrm{CH}_{2} \mathrm{Cl}_{2}$, (III) $5: 5(\mathrm{v} / \mathrm{v})$ n-hexane- $\mathrm{CH}_{2} \mathrm{Cl}_{2}$, (IV) $\mathrm{CH}_{2} \mathrm{Cl}_{2}$.

given medium. This will be discussed later. Figure 3 shows the variation of $P_{\mathrm{m}}$ with polarity of polymerization media for several initiator systems. The plots for pentacoordinate counteranions are not included. Approximately linear relations are observed for the Kirkwoodtype plots, ${ }^{9}$ except for those of $\mathrm{GaCl}_{4}{ }^{-}$. Thus, specific solvation need not be assumed for the steric course of propagation in these media.

\section{Counteranion Effect}

Since the polymerization was initiated by the addition of the triphenylmethyl cation, the counteranion structure in the propagating ionpair can be assumed to be the same as that in the initiator. The variation of $T_{\mathrm{p}}$ was previously related to the counteranion size based on this assumption. $^{1}$ Figure 4 is a similar relation which uses $P_{\mathrm{m}}$ instead of $T_{\mathrm{p}}$ and contains a larger number of counteranions. The counteranion radius was obtained, where necessary, as the sum of the bond length of the metal-halogen bond and the van der Waals radius of the halogen atom involved. The $P_{m}$ value increases with increasing counteranion sizes from $\mathrm{BF}_{4}{ }^{-}$ to $\mathrm{BCl}_{4}^{-}$via $\mathrm{ClO}_{4}^{-}$, then decreases at $\mathrm{AlCl}_{4}{ }^{-}$. This trend is very similar to that of $\operatorname{poly}(\alpha-$ 


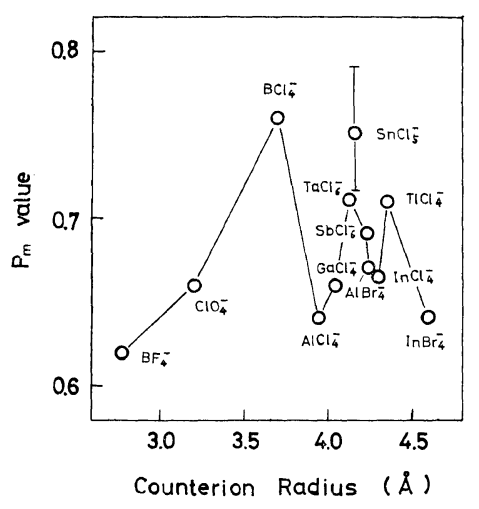

Figure 4. Dependence of the polymer structure on the counteranion radius: polymerization, $-76^{\circ} \mathrm{C}, 5: 5(\mathrm{v} / \mathrm{v}) n$-hexane- $\mathrm{CH}_{2} \mathrm{Cl}_{2}$.

methylstyrene) ${ }^{3}$ but the counteranion effect in the latter is not very clear for larger counteranions (radius $>4 \AA$ ).

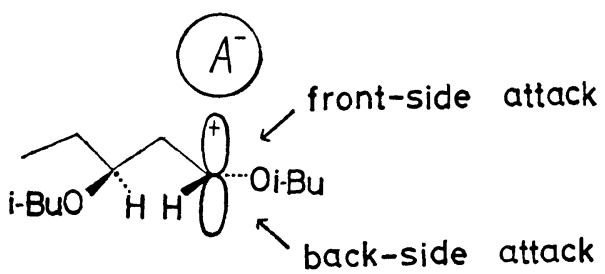

Scheme I. Steric course of propagation.

According to the model of the steric course of propagation proposed by us earlier, ${ }^{10}$ the most stable conformation of the growing polymer segment is the one shown by Scheme I. The front-side attack to the carbenium ion gives rise to a syndiotactic placement and the back-side attack to an isotactic placement. The relative ease of these modes of monomer attack is determined by the tightness of the growing ion-pair: isotactic propagation is preferred with a tight ion-pair.

The coulombic attraction of the oppositely charged ions decreases with increasing ion sizes, whereas the steric hindrance of the counteranion against monomer attack may simply increase with its size. It is probable that increasing steric hindrance renders the back-side attack favorable in the series, $\mathrm{BF}_{4}{ }^{-}-\mathrm{ClO}_{4}{ }^{-}-\mathrm{BCl}_{4}{ }^{-}$. Further increases in the anion size may decrease the tightness of the ion pair due to decreased electrostatic attraction. The overall relation of $P_{\mathrm{m}}$ and counteranion radii (Figure 4) showed periodic characteristics. This result cannot be accommodated by the simple combination of electrostatic attraction and steric hindrance. One possible explanation for this behavior is that the solvation state of the ion pair changes discretely with increasing counteranion radii. However, these explanations will need independent experimental support.

The decreasing $P_{\mathrm{m}}$ value with increasing medium polarity can be readily explained by loosening of the ion-pair.

\section{Influence of Initiator Concentration}

The peculiarity of the pentacoordinate counteranions $\left(\mathrm{SnCl}_{5}^{-}, \mathrm{SnBr}_{5}^{-}, \mathrm{ZrCl}_{5}^{-}, \mathrm{ZrBr}_{5}{ }^{-}\right)$has been noted in all the polymerization systems so far investigated. One of the features is that these counteranions give rise to $P_{\mathrm{m}}$ values larger than would be expected from their sizes. ${ }^{1,2}$ The other feature, which was discovered more recently, is that the polymer structure depends on the initiator concentration., ${ }^{3,4}$ This is clearly shown for poly(isobutyl vinyl ether) in Figure 5. The $P_{\mathrm{m}}$ value decreases from 0.8 to 0.7 by increasing the concentration of $\mathrm{Ph}_{3} \mathrm{C}^{+} \mathrm{SnCl}_{5}{ }^{-}$ from 1 to $9 \mathrm{mM}$. In contrast, the polymer structure was not affected by the initiator concentration in the cases of $\mathrm{Ph}_{3} \mathrm{C}^{+} \mathrm{InCl}_{4}{ }^{-}$and $\mathrm{Ph}_{3} \mathrm{C}^{+} \mathrm{SbCl}_{6}{ }^{-}$. When $\mathrm{Bu}_{4} \mathrm{~N}^{+} \mathrm{SnCl}_{5}^{-}$was added to the polymerization system (initiator: $\mathrm{Ph}_{3} \mathrm{C}^{+}$-

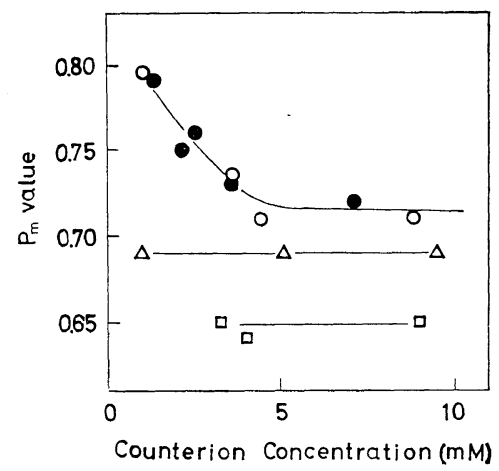

Figure 5. Influence of the counteranion concentration on the polymer structure: initiator, $(\bigcirc)$ $\mathrm{Ph}_{3} \mathrm{C}^{+} \mathrm{SnCl}_{5}{ }^{-}$, (O) $\mathrm{Ph}_{3} \mathrm{C}^{+} \mathrm{SnCl}_{5}-1 \mathrm{mM}$ and $n \mathrm{Bu}_{4} \mathrm{~N}^{+}$. $\mathrm{SnCl}_{5}^{-},(\triangle) \mathrm{Ph}_{3} \mathrm{C}^{+} \mathrm{SbCl}_{6}{ }^{-},(\square) \mathrm{Ph}_{3} \mathrm{C}^{+} \mathrm{InCl}_{4}-$; polymerization condition, $-76^{\circ} \mathrm{C}, 5: 5(\mathrm{v} / \mathrm{v}) n$-hexane$\mathrm{CH}_{2} \mathrm{Cl}_{2}$. 


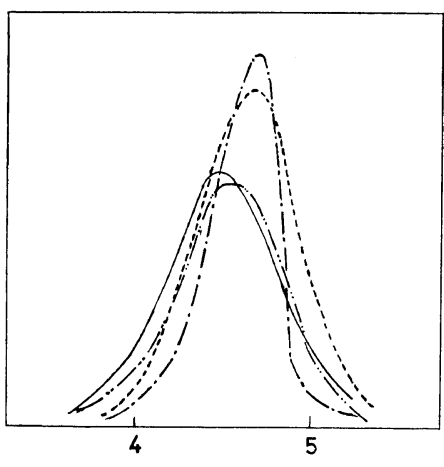

$\log M W$

Figure 6. Molecular weight distribution: $\mathrm{Ph}_{3} \mathrm{C}^{+} \mathrm{InCl}_{4}{ }^{-}, \quad 8: 2(\mathrm{v} / \mathrm{v}) \quad n$-hexane- $\mathrm{CH}_{2} \mathrm{Cl}_{2} ;---$ $\mathrm{Ph}_{3} \mathrm{C}^{+} \mathrm{SbCl}_{6}{ }^{-}, 5: 5(\mathrm{v} / \mathrm{v}) n$-hexane- $\mathrm{CH}_{2} \mathrm{Cl}_{2} ;-\cdots-$, $\mathrm{Ph}_{3} \mathrm{C}^{+} \mathrm{SnCl}_{5}-$, $5: 5(\mathrm{v} / \mathrm{v}) \quad n$-hexane- $\mathrm{CH}_{2} \mathrm{Cl}_{2} ;-\cdot-$, $\mathrm{Ph}_{3} \mathrm{C}^{+} \mathrm{SnCl}_{5}{ }^{-} 1 \mathrm{mM}+n-\mathrm{Bu}_{4} \mathrm{~N}^{+} \mathrm{SnCl}_{5}{ }^{-}, 5: 5(\mathrm{v} / \mathrm{v}) n-$ hexane- $\mathrm{CH}_{2} \mathrm{Cl}_{2}$.

$\left.\mathrm{SnCl}_{5}{ }^{-} 1 \mathrm{~m} M\right)$, a similar decrease in $P_{\mathrm{m}}$ was observed. The two series of the $P_{\mathrm{m}}$ changes can be accommodated by a single curve (Figure 5). Therefore, it is concluded that the $P_{\mathrm{m}}$ variation is related to the $\mathrm{SnCl}_{5}{ }^{-}$concentration.

These peculiarities can be related to the fluxional nature of the pentacoordinate counteranion. These anions can form halogen-bridged aggregates. ${ }^{11}$ As mentioned already, ${ }^{4}$ unaggregated pentacoordinate counteraions may form tighter ion-pairs than other anions of comparable size, if the former ions can assume the tetragonal pyramid configuration. At higher initiator concentrations, aggregated counteranions are formed, hence looser ion-pairs. The common-ion effect observed is consistent with this interpretation.

\section{Molecular Weight Distribution}

Higashimura, et al. recently found that two distinct propagating species were involved in the cationic polymerization of some vinyl monomers. ${ }^{12}$ Bimodal molecular weight distributions are observed in these cases. If such a situation exists, the interpretation of the counterion effect observed will become invalid. The molecular weight distributions of the polymers obtained in this study are all unimodal, suggesting that only one kind of propagating species is present under a given condition. It is interesting that a narrower distribution is obtained by adding
$\mathrm{Bu}_{4} \mathrm{~N}^{+} \mathrm{SuCl}_{5}^{-}$to the polymerization system initiated by $\mathrm{Ph}_{3} \mathrm{C}^{+} \mathrm{SnCl}_{5}^{-}$. Apparently, the structural difference of the polymer is derived from the difference in the nature of the propagating ion-pair, and not from the presence of varying amounts of distinct propagating species.

\section{CONCLUSION}

In a previous study on isobutyl vinyl ether, the variation of the polymer structure with the counteranion was discussed on the basis of the precipitation temperature, an indirect measure of the steric structure. In contrast, the polymer structure was directly determined from ${ }^{13} \mathrm{C}-\mathrm{NMR}$ spectroscopy in this study, and its variation could be discussed more clearly in terms of the counteranion size. The correlation between the steric structure and the counteranion size showed periodic characteristics, and this cannot be readily explained. The periodic influence was also observed in the polymerization of tert-butyl vinyl ether. ${ }^{5}$ Although the anion radius is probably the most important variable for explaining the counteranion effect, additional factors must be operating.

The peculiarity of the pentacoordinate anion was established and explained by its configurational characteristics. The observed commonion effect indicated the importance of the counteranion aggregation.

\section{REFERENCES}

1. T. Kunitake, Y. Matsuguma, and C. Aso, Polymer J., 2, 345 (1971).

2. Y. Matsuguma and T. Kunitake, ibid., 2, 353 (1971).

3. T. Kunitake and S. Tsugawa, Macromolecules, 8, 709 (1975).

4. T. Kunitake, T. Ochiai, and O. Ohara, J. Polym. Sci., Polym. Chem. Ed., 13, 2581 (1975).

5. T. Kunitake, J. Macromol. Sci.-Chem., A9, 797 (1975).

6. D. F. Shriver, "The Manipulation of Airsensitive Compounds," McGraw-Hill, New York, N. Y., 1969, Chapter 7.

7. S. Okamura, T. Higashimura, and I. Sakurada, J. Polym. Sci., 39, 507 (1959).

8. K. Matsuzaki, H. Ito, T. Kawamura, and T. Uryu, J. Polym. Sci., Part A-1, 11, 971 (1972).

9. J. G. Kirkwood, J. Chem. Phys., 2, 351 (1934); 
T. Kunitake, K. Takarabe, and S. Tsugawa

Chem. Rev., 24, 233 (1939).

10. T. Kunitake and C. Aso, J. Polym. Sci., Part A-1, 8, 665 (1970).

11. E. L. Muetterties and R.A. Schunn, Quart.
Rev., 20, 245 (1966).

12. T. Higashimura, O. Kishiro, K. Matsuzaki, and T. Uryu, J. Polym. Sci., Polym. Chem. Ed., 13, 1393 (1975). 